\title{
E Radiofrequency Ablation of the Supra- Orbital Nerve in the Treatment Algorithm of Hemicrania Continua
}

Paul Weyker MD, Christopher Webb MD, and Leena Mathew MD

From: Columbia University College of Physicians \& Surgeons. Columbia University

Medical Center/New York Presbyterian Hospital, New York, NY.

Dr. Weyker and Dr. Webb are Resident Physicians and Post Doctoral Fellows with the Department of Anesthesiology. Dr.

Mathew is Associate Clinical Professor of Anesthesiology. Associate Director Pain Fellowship, Division of Pain Medicine, Columbia University College of Physicians \& Surgeons, Columbia University Medical Center/New York Presbyterian Hospital, New York, NY.

Address Correspondence: Leena Mathew, MD Columbia University College of Physicians \& Surgeons/Columbia University Medical Center|Presbyterian Hospital Dept of Anesthesiology 622 West 168th Street Presbyterian Hospital Rm 505 New York, NY

Email:Im370@columbia.edu

Disclaimer: There was no external funding in the preparation of this manuscript. Conflict of interest: None.

Manuscript received: 10/25/2011

Revised manuscript received: 06/07/2012 Accepted for publication: 06/15/2012

Free full manuscript: www.painphysicianjournal.com
Hemicrania continua $(\mathrm{HC})$ is an uncommon primary headache disorder in which the diagnosis centers on unilaterality and its absolute responsiveness to indomethacin. We describe 3 patients with a long standing history of headache diagnosed as hemicrania continua. There was profound response to indomethacin which was limited by side effects. In one patient the therapy with indomethacin was limited secondary to comorbidities. Initial diagnostic blockade provided significant relief of symptoms based on which radio-frequency ablation of the supraorbital nerve was performed with substantial improvement in symptoms. Traditionally, hemicrania continua has been managed exclusively with oral analgesics and is defined by its singular response to indomethacin. Radio-frequency ablation (RFA) has been reported in the literature for multiple indications. This case series is unique in that it describes 3 patients diagnosed with hemicrania continua with pain referred in the supraorbital nerve distribution, who underwent radiofrequency ablation of the supraorbital nerve with resultant resolution of headaches.

Traditionally, hemicrania continua has been managed exclusively with oral analgesics and is defined by its singular response to indomethacin. This report is unique in that it describes three patients diagnosed with hemicrania continua with pain referred in the supraorbital nerve distribution who underwent radiofrequency ablation of the supraorbital nerve with resultant resolution of headaches. After the RFA medical management was minimal to none in both patients. Though the utility and cost efficacy of RFA of peripheral nerves needs to be confirmed in well-designed trials we present these cases as an example of how this minimally invasive technique can safely provide analgesia in a difficult to treat cephalgia. Moreover if precise anatomical localization of the headache is possible then diagnostic blockade of the appropriate peripheral nerve may be performed followed by radiofrequency ablation to provide potentially more sustained analgesia in patients where medical management is ineffective or poorly tolerated.

Key words: Headache, hemicrania continua, radio-frequency ablation

Pain Physician 2012; 15:E719-E724

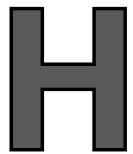
eadache disorders are some of the most common illnesses for which patients visit their primary care doctors (1). Ranging from migraines, primary headache disorders, and neuralgias, to disabling cluster headaches, these illness can have a profound impact on a patient's overall health and mental stability $(1,2)$.
Hemicrania continua (HC) is an uncommon primary headache disorder in which the diagnosis centers on unilaterality and its responsiveness to indomethacin (3-5). According to the international classification of headache disorders, $\mathrm{HC}$ is a continuous, unilateral, indomethacin-responsive headache lasting longer than 3 months with fluctuating periods of moderate 
intensity to severe pain exacerbations accompanied by dysautonomia (conjuctival injection and/or lacrimation, nasal congestion and/or rhinorrhea, ptosis and/or miosis) (Table 1) (2). Upon diagnosis, HC can be further categorized into a continuous form and a remitting form, with the latter being less common $(6,7)$.

Since its initial characterization, over 130 cases of $\mathrm{HC}$ have been reported in the literature (4). While the epidemiology of $\mathrm{HC}$ has yet to be fully defined, some studies suggest a prevalence of 1 in 1,800 patients with a small female preponderance ranging from 1.6:1 to 1.8:1 $(8,9)$. While the exact cause of $\mathrm{HC}$ has yet to be fully identified, functional neuroimaging and positron emission tomography studies have demonstrated the involvement of subcortical structures with activation in the ipsilateral dorsal rostral pons, ventrolateral midbrain, and contralateral posterior hypothalamus $(10,11)$. These findings suggest that based on neuronal activation patterns, HC may actually be on a spectrum of headache disorders similar to migraines and trigeminal autonomic cephalgias (10).

Currently, the mainstay of treatment for $\mathrm{HC}$ is indomethacin $(5,7,12)$. While the exact mechanism is unknown, studies have suggested that indomethacin crosses the blood-brain barrier and inhibits the activation of the posterior hypothalamus, dorsal rostral pons, and ventrolateral midbrain (10). Starting doses are usually 25-300 mg/d with doses tapered down to the minimum effective dose necessary to prevent pain episodes (5). While one case report did demonstrate a marginal effect of supraorbital nerve blocks on decreasing visual analog scale pain values, greater occipital nerve and minor occipital nerve blocks failed to provide any pain relief (13).
These case reports appear to describe the first uses of radiofrequency ablation (RFA) for treatment of $\mathrm{HC}$.

\section{Case Report}

\section{Patient 1}

The first patient is a 77-year-old woman with an 11-month history of right-sided headache, referred to the Pain Center with a diagnosis of HC. The pain was strictly a unilateral, constant, dull pain localized in the superior aspect of the right periocular region radiating to the frontal region without extension to the temporal region. There were no precipitating factors and her neurological exam was normal. After failing several analgesics, including several nonsteroidal antiinflammatories, gabapentin, and baclofen, a course of indomethacin therapy had provided resolution of symptoms (Table 2) but had to be stopped because of severe gastritis.

Subsequently, a trial of pregabalin therapy provided partial analgesia, but the therapy was limited by intolerable sedation. She presented with a request to consider invasive interventional options. Based on the anatomic localization of pain, a right supra-orbital nerve block was performed with $2 \mathrm{~mL}$ of bupivacaine $0.25 \%$ and $10 \mathrm{mg}$ of triamcinolone, which decreased her pain score on a numeric rating score to $2 / 10$ from a baseline pain score of $7 / 10$. She did have resultant ptosis which was an acceptable side effect for her. Pain relief lasted for 10 days. Upon replicating these results again with another local anesthetic block with concordant pain relief, RFA of the supraorbital nerve was performed.

Table 1:International Classification of Headache Disorders: Diagnostic Criteria for Hemicrania Continua.

\begin{tabular}{|l|l||}
\hline \multicolumn{2}{|l||}{ Description: Constant, severe, unilateral headache for $>\mathbf{3}$ months that responds to indomethacin. } \\
\hline A. & At least 5 attacks fulfilling criteria B-D \\
\hline B. & Severe or very severe unilateral orbital, supraorbital, and/or temporal pain lasting 15-180 minutes if untreated \\
\hline C. & Headache is accompanied by at least one of the following: \\
\hline & -ipsilateral conjunctival injection and/or lacrimation \\
\hline & -ipsilateral nasal congestion and/or rhinorrhea \\
\hline & -ipsilateral eyelid edema \\
\hline & -ipsilateral miosis and/or ptosis \\
\hline & -a sense of restlessness or agitation \\
\hline D. & Attacks have a frequency from one every other day to 8 per day. \\
\hline E. & Not attributed to another disorder \\
\hline
\end{tabular}


Supraorbital Nerve RFA in the Treatment of Hemicarania Continua

Table 2. Illustration of the duration of symptoms and number of previous treatments prior to undergoing radiofrequency ablation.

\begin{tabular}{|c|c|c|}
\hline Patients $(\mathbf{n}=\mathbf{3})$ & Length of Symptoms(months) & Previous Treatments \\
\hline 1 & 11 & Indomethacin,pregabalin \\
\hline 2 & 8 & Gabapentin, pregabalin, tizanidine, baclofen \\
\hline 3 & 6 & $\begin{array}{c}\text { NSAIDs } \\
\text { Gabapentin, pregabalin, } \\
\text { amitriptyline, duloxetine } \mathrm{HCl}, \\
\text { baclofen, } \\
\text { topical lidocaine, } \\
\text { acetaminophen, } \\
\text { physical therapy }\end{array}$ \\
\hline
\end{tabular}

Table 3 illustrates the number of radiofreqency $(R F)$ treatments for each patient, the duration of analgesia after the radiofrequency treatments and posttreatment consumption of analgesics. \{This should be the table legend, not a footnote\}

\begin{tabular}{||l|l|l|l||}
\hline \hline Patients (n = 3) & \multicolumn{1}{|c|}{ Number of RF Treatments } & \multicolumn{1}{|c|}{$\begin{array}{c}\text { Duration of } \\
\text { Analgesia(months) }\end{array}$} & \multicolumn{1}{|c|}{$\begin{array}{c}\text { Posttreatment Consumption of Analgesics } \\
\text { for Breakthrough Pain }\end{array}$} \\
\hline 1 & $\begin{array}{l}\text { Session 1: Pulsed RF followed by } \\
\text { thermal RFA } \\
\text { Session 2: Thermal RFA }\end{array}$ & 7 months & None \\
\hline 2 & 1 RFA & $>12$ months & None \\
\hline 3 & 1 RFA & $>8$ months & None \\
\hline
\end{tabular}

The patient was placed in the supine position and standard American Society of Anesthesiologists monitors were applied. A skin wheal was created using lidocaine $1 \%$ at the junction of the nasal root and supraorbital ridge. The supraorbital notch was easily palpated in the medial aspect of the supraorbital ridge. A $22 \mathrm{G}$ insulated needle with a noninsulated $4 \mathrm{~mm}$ tip was slowly introduced at a perpendicular angle immediately superior to the supraorbital notch and then flattened to allow the tip of the needle to slide into the notch. Once this was appreciated the needle was further advanced about $0.5 \mathrm{~cm}$ and the position was confirmed with fluoroscopy guidance. Sensory stimulation at $50 \mathrm{~Hz}$ and 0.3 $\mathrm{mA}$ produced paresthesia in the periocular region that extended into the frontal region, concordant with pain distribution.

Pulsed RFA with a tip temperature of $42^{\circ} \mathrm{C}$ for 120 seconds was initially performed because of uncertainty regarding her tolerance to the procedure. She was noted to tolerate the procedure well and a second lesion was created using continuous thermal RFA with a tip temperature of $80^{\circ} \mathrm{C}$ for 60 seconds. She tolerated the procedure uneventfully and was discharged home.

Over the next 5 days the patient's symptoms resolved completely and she remained pain free without the use of breakthrough medications for 7 months. Dur- ing this time she did note numbness in the supraorbital region and minor ptosis of the right eyelid that was an acceptable side effect. Eight months later she returned with recurrence of symptoms. We felt that there was a possibility that pulsed RFA would be sufficient for amelioration of pain and perhaps avoid the ptosis side effect. The supraorbital nerve was localized and a pulsed RFA was done for 120 seconds with a tip temperature of $42^{\circ} \mathrm{C}$. However, the patient returned in 2 weeks with minimal improvement in analgesia and continued symptoms with recurrence of the baseline numeric pain score of $7-8 / 10$. The decision was made to repeat continuous thermal RFA of the right supraorbital nerve. This was accomplished with a maximum tip temperature of $80^{\circ} \mathrm{C}$ for 60 seconds. The patient experienced complete resolution of symptoms after 4 days of this treatment with no requirement for posttreatment analgesics (Table 3 ). The patient has remained pain-free for over 12 months.

\section{Patient 2}

The second patient is a 54-year-old man who presented with an 8-month history of headache with a diagnosis of $\mathrm{HC}$ (Table 2). He was unable to initiate indomethacin treatment because of ongoing aspirin therapy after a cerebrovascular accident. The patient 
also had a history of peptic ulcer disease. He had minimal improvement while experiencing side effects with adjuvant analgesic therapy trials using baclofen, gabapentin, pregabalin, and tizanidine. He was reluctant to consider further pharmacotherapeutic trials because of side effects. Pain was localized extending from the left upper eyelid along the frontal aspect to the middle of the scalp.

Based on the localization of his headache, a blockade of the left supraorbital nerve was performed with one $\mathrm{ml}$ of $0.25 \%$ bupivacaine and $10 \mathrm{mg}$ of triamcinolone, which provided greater than a $90 \%$ improvement in pain for 10 days. This effect was replicated for 14 days with a repeat block using one $\mathrm{ml}$ of $0.25 \%$ bupivacaine and $10 \mathrm{mg}$ of triamcinolone. Continuous RFA of the left supra-orbital nerve was done using the same technique as previously described. Over the next 4 days the patient had substantial improvement in symptoms that did not requiring breakthrough medications. The improvement lasted for 12 months with continued ongoing relief at the time of this submission (Table 3).

\section{Patient 3}

The third patient is a 45-year-old man in good health with a 6-month history of constant left-sided headache (Table 2). The pain was constant in the left side extending from the left eyebrow to mid scalp. The pain was nonpositional and throbbing, with intermittent episodes of exacerbation associated with tearing and nasal congestion. There was no history of trauma or seizures. He had never experienced migraine or cluster headache prior to this.

An extensive workup, including lumbar puncture and imaging studies, showed no conclusive findings. He had numerous medication trials during the 6 months, including antidepressants, anticonvulsants, opioids, muscle relaxants, nonsteroidal anti-inflammatory medications, and acetaminophen. He had also attempted topical agents, including lidocaine. He noted no improvement from these and was experiencing a tremendous decrease in his quality of life and work capacity as a result. He also tried physical therapy for 3 months to improve his posture and paracervical muscle spasm.

When he presented at the Pain Center, he was extremely frustrated and was taking no medications. Indomethacin therapy was initiated for a presumed diagnosis of HC. This provided complete resolution of symptoms; however, he was unable to tolerate the dose of $50 \mathrm{mg}$ orally twice daily due to gastrointestinal distress despite concomitant proton pump inhibitor therapy. Indomethacin therapy was discontinued after 3 weeks, and based on the mapping of the pain in the distribution of the left supraorbital nerve, a supraorbital nerve block was done using one $\mathrm{ml}$ of $0.25 \%$ bupivacaine with $10 \mathrm{mg}$ of triamcinolone. He developed numbness in the concordant distribution with mild ptosis and had pain resolution. Pain relief lasted for 5 days. The local anesthetic with steroid blockade was repeated and the effect was replicated yet again for 12 days.

At this point we decided to proceed with continuous RFA of the left supraorbital nerve as initially described. The patient reported immediate improvement in pain and subsequently continued to improve further. At the end of 7 days he had resolution of his left-sided headache and did not require any breakthrough pain medications. The analgesic effects have persisted for over 8 months at the time of this submission, with no analgesic use (Table 3).

\section{Discussion}

$\mathrm{HC}$ is a chronic primary headache disorder characterized by unilateral continuous pain that may fluctuate in intensity without complete resolution. Pain exacerbations with $\mathrm{HC}$ are often associated with autonomic features such as lacrimation, nasal congestion, conjunctival injection, ptosis, and facial flushing. The hallmark of $\mathrm{HC}$ is the resolution of symptoms with indomethacin treatment (8). Responsiveness to indomethacin treatment is the defining diagnostic factor differentiating HC from other chronic unilateral headaches. As such, an indomethacin trial is recommended early on in the diagnosis and treatment of unilateral headache disorders (12).

Local anesthetic nerve blockade is highly effective in other primary headache disorders such as supraorbital neuralgia, but does not provide long-term relief. Nonetheless, a positive response to local anesthetic nerve blockade may be predictive of a good outcome from RFA of that nerve $(14,15)$. Once symptomatic relief is confirmed with a peripheral nerve block procedure, RFA can be a reasonable therapeutic option for definitive treatment of this chronic headache disorder.

In the cases described above, the patients met full diagnostic criteria for $\mathrm{HC}$, as evidenced by presenting symptomatology and absolute responsiveness to indomethacin therapy. Patient \#2 was unable to have a trial of indomethacin because of concomitant comorbidities. Chronic treatment with indomethacin can frequently cause unacceptable side effects such as gastrointestinal irritation and renal dysfunction. In fact, approximately 
$20 \%$ of patients receiving indomethacin for $\mathrm{HC}$ discontinue treatment due to adverse side effects (5). Moreover, although the current definition of $\mathrm{HC}$ requires absolute responsiveness to indomethacin, some patients with the clinical phenotype of $\mathrm{HC}$ do not respond to indomethacin treatment (7).

All the patients were referred to the Pain Center with a diagnosis of HC. Moreover, the constellation of signs and symptoms exhibited by our patients corresponded to a diagnosis of $\mathrm{HC}$ localized in the anatomic distribution of the supraorbital nerve. The inability to tolerate indomethacin and the inadequacy of alternative pharmacotherapy led to the invasive interventional alternatives. Local anesthetic blockade of the ipsilateral supraorbital nerve resulted in excellent analgesia and subsequent RFA of the nerve conferred a long-lasting resolution of symptoms. The side effects of the procedure were residual numbness in the supraorbital nerve distribution and mild ptosis, which were both considered by the patients to be acceptable.

\section{Conclusion}

Traditionally, HC has been managed exclusively with oral analgesics and is defined by its singular response to indomethacin. It is likely that some patients diagnosed with HC may in fact suffer from cranial neuralgias. RFA has been reported in the literature for multiple indications involving peripheral neuralgias.

This report is unique in that it describes 3 patients diagnosed with $\mathrm{HC}$ with pain referred in the supraorbital nerve distribution. After positive analgesic response with local anesthetic blockade, they underwent RFA of the supraorbital nerve with resultant resolution of headaches. After RFA, medical management was minimal in all 3 patients for at least 7 months. Fluoroscopy

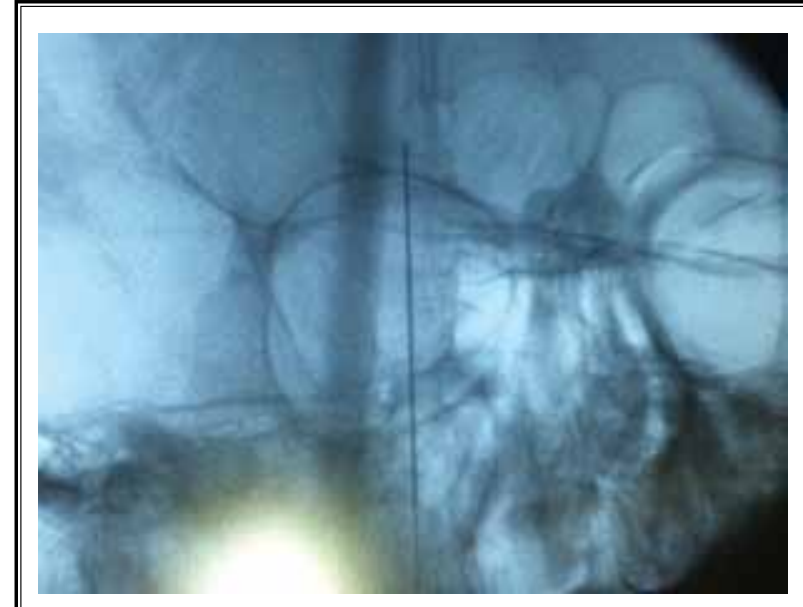

Fig. 1. Fluoroscopic guided needle placement.

ensured accurate needle placement in the supraorbital notch. Though the utility and cost efficiency of peripheral nerve RFA needs to be confirmed in well-designed trials, we present these cases as an example of how this minimally invasive technique safely provided analgesia in a difficult-to-treat cephalgia secondary to HC.

\section{Disclosures/Conflict of Interest}

The authors state that they have no financial disclosures or conflict of interest.

\section{References}

1. Becker A, Iverson CD, Reed MF, Calonge N, Miller SR, Freeman LW. A study of headache in North American primary care. Report from the Ambulatory Sentinel Practice Network. J Royal College Gen. Practit 1987; 37:400-403.

2. Olesen J, Bes A, Kunkel R, Lance WJ, Nappi G, Pfaffenrath V, Rose CF, Schoenberg SB, Soyka D, Tfelt-Hansen P, Welch
MAK, Wilkinson M, Bousser GM, Diener $\mathrm{CH}$, Dodick D, First M, Goadsby P, Gobel $\mathrm{H}$, Lainez JM, Lance WJ, Lipton R, Sakai F, Schoenen J, Silberstein DS, Steiner JT The International Classification of Headache Disorders: 2nd edition. Cephalalgia 2004; 24 Suppl 1:9-160.

3. Sjaastad O, Spierings EL, Saunte C, Wysocka Bakowska MM, Sulg I, Fredrik- sen TA. "Hemicrania continua". An indomethacin responsive headache. II. Autonomic function studies. Cephalalgia 1984; 4:265-273.

4. Peres MF, Valenca MM, Goncalves AL Misdiagnosis of hemicrania continua. Expert Rev. Neuro 2009; 9:1371-1378.

5. Rossi P, Tassorelli C, Allena M, Ferrante E, Lisotto C, Nappi G. Focus on ther- 
apy: hemicrania continua and new daily persistent headache. J Headach and Pain 2010; 11:259-265.

6. Cittadini E, Goadsby PJ. Update on hemicrania continua. Curr Pain Head Rep 2011; 15:51-56.

7. Marmura MJ, Silberstein SD, Gupta M. Hemicrania continua: Who responds to indomethacin? Cephalalgia 2009; 29:300-307.

8. Cittadini E, Goadsby PJ. Hemicrania continua: A clinical study of 39 patients with diagnostic implications. Brain 2010; 133:1973-1986.
9. Newman LC, Lipton RB, Solomon S. Hemicrania continua: Ten new cases and a review of the literature. Neurology 1994; 44:2111-2114.

10. Matharu MS, Cohen AS, McGonigle DJ, Ward N, Frackowiak RS, Goadsby PJ. Posterior hypothalamic and brainstem activation in hemicrania continua. Headache 2004; 44:747-761.

11. Cohen AS, Goadsby PJ. Functional neuroimaging of primary headache disorders. Exp Rev Neuro 2006; 6:1159-1171.

12. Peres MF. Hemicrania continua: Recent treatment strategies and diagnos- tic evaluation. Curr Neurology and Neuroscience Reports 2002; 2:108-113.

13. Antonaci F, Pareja JA, Caminero AB, Sjaastad O. Chronic paroxysmal hemicrania and hemicrania continua: Anaesthetic blockades of pericranial nerves. Functional Neurology 1997; 12:11-15.

14. Pareja JA, Caminero AB. Supraorbital neuralgia. Curr Pain Head Rep 2006; 10:302-305.

15. Bogduk N. Role of anesthesiologic blockade in headache management. Curr Pain Head Rep 2004; 8:399-403. 